Marquette University

e-Publications@Marquette

9-1-2016

\title{
Open Government and the Politics of Public Knowledge in the United States
}

Philip Rocco

Marquette University, philip.rocco@marquette.edu

This is the peer reviewed version of an article that appeared in Public Administration, Vol. 94, No. 3 (September 2016): 846-853. DOI.This article may be used for non-commercial purposes in accordance With Wiley Terms and Conditions for self-archiving. (C) 2016 John Wiley \& Sons, Inc. Used with permission.

Philip Rocco was affiliated with the University of Pittsburgh at the time of publication. 


\title{
OPEN GOVERNMENT AND THE POLITICS \\ OF PUBLIC KNOWLEDGE IN THE UNITED STATES
}

\author{
Philip Rocco, University of Pittsburgh \\ pbr8@pitt.edu
}

Forthcoming, Public Administration

Secrecy in the Sunshine Era: The Promise and Failure of US Open Government Laws Jason Ross Arnold

University Press of Kansas, 2014, 566 pp. \$28.07, ISBN: 0700619925

Legislating in the Dark: Information and Power in the House of Representatives

James M. Curry

University of Chicago Press, 2015, 264 pp., \$30.00, ISBN: 9780226281711

Watchdogs on the Hill: The Decline of Congressional Oversight of US Foreign Relations Linda L. Fowler

Princeton University Press, 2015, 280 pp.,\$17.97, ISBN: 9780691151625

The Rise of the Right to Know: Politics and the Culture of Transparency, 1945-1975.

Michael Schudson

Belknap Press, 2015, 368 pp., \$29.95, ISBN: 9780674744059

Since his inauguration in 2009, President Barack Obama has emphasized his administration’s commitment to improving public knowledge about what government does. On his first day in office, Obama signed a "Memorandum on Transparency and Open Government," which set the course for a series of executive orders requiring federal agencies to make "open and machine readable data” a default policy. These efforts culminated in data.gov, an online repository for government-collected information (Obama 2009).

Policy ideas like transparency and openness have long been identified with the goal of holding democratic governments (and sometimes the private sector) responsible (Shils 1956; 
Rourke 1961). Yet beyond mere accountability, Obama’s rhetoric suggests that data and transparency can be positive instruments of public policy-a means of shaping social and economic behavior that differs qualitatively from fiscal incentives or regulatory punishments. As his 2013 Executive Order puts it, “making information resources easy to find, accessible, and usable can fuel entrepreneurship, innovation, and scientific discovery that improves Americans’ lives and contributes significantly to job creation” (Obama 2013).

In the past year, the administration has begun to put its data initiatives to use-not only to monitor the performance of federal agencies, but also to alter policy debates in a variety of arenas. The Department of Education launched a College Scorecard, which will allow consumers to evaluate colleges and universities that receive federal funds with new metrics that evaluate affordability and labor-market outcomes (Turner 2015). The Centers for Medicare and Medicaid Services have also imposed new transparency requirements on doctors. They require the publication of consumer information on, among other things, "how reliably physicians provide follow-up care for depression and high blood pressure, and how well they monitor patients for healthy weight and tobacco use” (Evans 2015).

Such initiatives are animated by the idea that the state can leverage public knowledge as an instrument of public policy. Rather than directly prohibiting or incentivizing certain behaviors on the part of government officials or market actors, however, transparency programs work indirectly. The hope of transparency advocates is that information will either enable democratic publics (or government watchdogs) to mobilize behind new policies or permit consumers to (privately) alter their choices about consumption in the market.

Yet transparency programs have their classical downsides. As Francis Rourke put it in 1961, "there is no simple way of reconciling the conflicting claims of publicity, secrecy, and 
democracy” (Rourke 1961: 226). Rather, as the books under review here suggest, transparency carries with it a distinctive politics. Given their symbolic value, “Open Government” initiatives are easy enough to enact. Yet in practice, such reforms contend with the entrenched incentives and habits of three vital sets of actors: the targets of transparency reforms themselves; government officials charged with deploying and implementing the tools of transparency; and the public audiences that these policies are intended to inform. Often, transparency programs fail to reshape how these actors behave, and hence fail to ignite meaningful changes in the direction or scope of public policy. In some cases, policymakers have also developed powerful new tools to restrict the flow of information, which remain outside the purview of sunshine laws altogether.

\section{ENFORCING SUNSHINE}

A core presumption of transparency advocates is that government programs can compel the production of information that is accurate, up-to-date, and focused on the appropriate empirical phenomena for the governing task at hand. However, were food manufacturers—-to take one example—able to evade packaging requirements by giving new names to unsafe ingredients, it is doubtful that transparency would enable informed consumer choices. To work properly, freedom-of-information laws must make it difficult for government agencies or market actors to claim exemptions or invent new categories of private information. Otherwise, the information legislators or citizens can procure is unlikely to enable them to observe the behaviors such reforms seek to guard against, let alone influence policy.

Jason Ross Arnold's Secrecy in the Sunshine Era is the definitive account of why enforcing sunshine laws has proven to be so difficult. As Arnold argues, open government laws like the Freedom of Information Act (FOIA), the Federal Advisory Committee Act (FACA), and 
the Public Records Act are politically popular, and are often enacted by broad majorities. Nevertheless, these laws do little to change the culture of the officials they were designed to police. And since those officials are the ones with material possession of the files themselves, their beliefs and preferences matter. Among Executive Branch officials, a "governing ideology" that emphasized the value of secrecy for making good public policy persisted even after sunshine laws were passed. This ideology was arguably most pronounced during the Bush-Cheney administration, whose officials often articulated a "strong version of the unitary executive theory,” in which the President's unique constitutional authority in matters of foreign policy allowed it to share information with Congress and the public on a strictly voluntary basis (41). Even in the absence of a clearly articulated ideology, sunshine laws give the Executive Branch ample opportunities for circumvention. Presidents can take advantage of economic or national security crises as “unsettled times," rhetorically constructing broader public support for secrecy. But rather than pressing for the retrenchment of open government laws, presidents have layered on new policies—such as the Critical Infrastructure Information Act of 2002— that create novel categories of protected information, limiting the scope of existing policies. Presidents have developed legal rationales for defending secrecy in the courts, gradually converting the meaning of existing laws. Several administrations have been successful in protecting the privacy of presidential task forces, for instance, by arguing that their members were in fact "guests" and "visitors," and hence not subject to the Federal Advisory Committee Act.

The failure of sunshine laws to achieve institutional "lock in" has allowed excessive secrecy to persist, restricting public involvement in the policymaking process. As Arnold documents, all post-FOIA presidential administrations have found ways of exempting themselves from the law. Between 1998 and 2008, the rate of fully granted FOIA requests fell by 
roughly half. The percent of meetings by FACA-covered government organizations that were closed to the public increased from 20 percent in 1974 to well over 60 percent in 2004. This secrecy has helped to shroud more than foreign policy decisions where Executive Branch dominance is to be assumed; indeed, Arnold demonstrates that secrecy continues to pervade domestic policy, such as the White House muffling of scientific findings on climate change, regulatory information about industrial pollution and the identity of businesses selling contaminated meat.

While Executive Branch secrecy has been a persistent trend in the "Sunshine Era," the rise of a stronger variant of unitary executive theory in the White House has also led to a marked increase in some forms of circumvention. Since the Bush-Cheney administration, Arnold shows, there has been a shift in how officials at the White House Office of Legal Counsel (OLC) have circumvented FOIA requirements to promptly publish "statements of policy and interpretations which have been adopted.” Under Bush-Cheney, the vast majority of OLC's opinions were published four or more years after they were enacted.

While Arnold argues that comparisons across successive presidential administrations are difficult to carry out, he effectively shows that the Obama administration’s Open Government initiatives are meaningfully different than the efforts of past administrations, even if they have not contributed to a shift in the overall direction of policy. In particular, he details the administration's efforts at changing the rules on FACA and FOIA, as well as the rollout of more concrete transparency guidelines across agencies that control access to proprietary scientific information. These measures have had promising early-stage consequences. Yet as suggested by recent revelations of excessive Executive Branch secrecy about the National Security Administration's wiretapping program, the culture of secrecy is baked into the day-to-day 
routines of some federal agencies. This raises the bar that any single reform will have to clear in order to be considered a success.

Arnold's analysis forces us to consider a pragmatic question about transparency reforms: given the political consensus about "open government” as a tool for enhancing policy responsiveness in a democracy, why do such efforts often fail? The problem is that, while transparency programs mobilize constituencies from journalists to entrepreneurial watchdogs across the political spectrum, they often do little to alter the powerful incentives government officials have to protect information that allows them to shape the course of policy in a fragmented political system. If it is true that the preferences of bureaucratic agents_-rather than legislative principals_ - are to blame, the search for "sunshine” cannot be limited to transparency policies alone. Indeed, Arnold's work suggests that a response to agents' entrenched preferences for secrecy—possibly in the process of recruitment, retention, and promotion—may be an important complementary reform.

\section{COMBATING VISION LOSS}

Of course, obstreperous officials are not solely responsible for ineffective transparency programs. While the idea of “open government” appears natural and spontaneous, an “original condition" of democratic societies, it does not happen in the absence of "boots on the ground.” In practice, this means existence of a "monitor" who can not only compel the release of information to the public, but also translate "raw" data about action in government or the marketplace into meaningful public knowledge. ${ }^{1}$ Monitors thus must know which information to procure, when to procure it, and how to ensure that its dissemination changes behavior, either through markets or

\footnotetext{
${ }^{1}$ On the weakness of "raw" data as a concept, see Gitelman (2013).
} 
politics. Gaining such knowledge, much less using it, requires substantial investment by legislative or regulatory principals. Yet these actors will be unlikely to make such efforts unless activities such as bureaucratic oversight and consumer protection allow them to build professional and political reputations.

There is a mountain of evidence on this point tucked within Watchdogs on the Hill, Linda Fowler's succinct yet probing study of the decline of congressional oversight of US foreign relations. In a carefully designed analysis that blends case studies with an explosion of original quantitative data, Fowler reveals how variations in partisan, professional, and institutional incentives led to significant gaps in the Senate's capacity to effectively keep a "watchful eye” on executive-led foreign policy initiatives. To explain declining Senate oversight, Fowler shows how shifting expectations of senators' allocation of time weakened their ability to become foreign policy specialists and how media attention to the Senate Armed Services and Foreign Relations committees decreased. These gradual institutional shifts helped to dampen members' incentives to routinely monitor executive branch activity on military interventions and diplomatic relations. Given the vast and expanding nature of the Executive Branch’s foreign policy portfolio, the erosion of "regular order" on these committees sapped their capacity to use transparency as an instrument of policy change, reflected in a major decline in hearings on both committees in the mid-1990s.

If institutional change matters to committees' use of oversight tools, so too do committees’ own stable institutional identities. Not all committees are predisposed to use transparency as a policy tool in the same way. The culture of the Armed Services Committee was one that restricted partisan policy conflict, focusing instead on expanding the Pentagon's budget. Its members circled the wagons around Republican presidents and used hearings to prop up 
public confidence in the military. The result was that Armed Services did not engage in regular oversight, except after major military deployments or other policy incidents such as the revelation of appalling health conditions at Walter Reed Army Hospital in 2007. By contrast, Foreign Relations developed a more robust culture of policy debate in which majority leaders used the committee to enhance their party's reputation. As a result, the committee tended to exercise greater oversight during periods of divided government—in particular when Democratic leadership faced a Republican president—and on issues that accentuated policy failures of the President's party. For example, despite the comparatively small national-security stakes of US involvement in the 1992 humanitarian crisis in Somalia, Democratic leaders on Foreign Relations used the incident to exploit the George H.W. Bush’s failure to commit troops to attack Republicans' competence in foreign policy.

In exchange for tightly focusing its analysis on two committees over time, Fowler’s study affords a level of precision on the politics of oversight that prior studies have lacked. In particular, Watchdogs suggests that transparency-promoting institutions like oversight committees are in many ways only as effective as the incentives for discretionary policymakers to use them. The increasing challenge of investing in oversight is not unique to congressional committees. Recently, congressional budget cuts to Offices of inspectors general (OIGs) have limited the kinds of audits, investigations, and other enforcement actions that allow government to ensure the effective spending of money and to avoid misappropriation of funds (Hudak and Wallack 2015). So while the demand for oversight must be balanced with other policy goals, greater attention is warranted to how fiscal and professional realities affect policymakers' desire to serve as monitors. As Fowler shows, we cannot ignore the difficulty of oversight in the face of 
legislative agendas, policy commitments, and professional incentives out of joint with the cause of transparency.

\section{TRANSPARENCY CULTURE AND ITS DISCONTENTS}

While government watchdogs are significant, the implementation of transparency reforms is not simply a matter for professionals or policy elites. A core assumption of the open-government philosophy is that the state can leverage the public itself as an instrument of policy change. By opening up market or government activity to public scrutiny, transparency reforms seek to improve the likelihood that citizens will become mobilized to address significant policy problems. Budget transparency programs, for example, seek to allow “citizens to play a key role in identifying, discussing, and prioritizing public spending projects” (Open Government Partnership 2013: 10). Other measures_food-labeling or physician-rating initiatives, for instance- - target consumers in the hope that they will use information to make more informed choices in the marketplace.

Given the public’s important role in transparency reforms, the Obama Administration has made it a priority for government agencies to “identify key audiences” for their data and to “endeavor to publish high-value information for each of those audiences in the most accessible forms and formats” (Obama 2009). In an information-rich world, however, voters and consumers may still lack the resources, time, or taste for using the information that transparency initiatives produce (Lee et al. 2014). Moreover, what historian Michael Schudson calls the "culture of transparency” — defined by a public preference for information and institutionalized practices of disclosure-is a more recent, and perhaps more fragile, development than it appears at first blush. 
Schudson's The Rise of the Right to Know shows that we cannot understand the politics of transparency in the United States without appreciating the role of public culture. Most importantly, Schudson finds that the idea of transparency itself is a fairly recent entry in the democratic lexicon. The language of disclosure was largely missing from American politics prior to 1945 . Yet in the early days of the cold war, prominent journalist groups-including the American Society of Newspaper Editors—-began to invoke the idea of a quasi-constitutional "right to know." This idea became essential to future political efforts to shed sunlight on the federal bureaucracy, food production processes, and industrial pollution.

While US transparency reforms such as FOIA and the National Environmental Protection Act were the product of specific political disputes, often between Congress and the Executive Branch, they helped to underwrite the development of public-interest law firms, consumer groups, and environmental organizations, many of which began to use new government-provided information as the basis for political activism. Law itself is hardly the most important actor in the story, however. Rather, the effectiveness of transparency reforms also depended on changes in American culture, such as the rapid growth in college attendance by a more diverse cross-section of individuals and a strengthened focus on "critical inquiry" among educational institutions. Changing professional norms, especially among a journalistic corps increasingly skeptical of established elites, are also well documented in Schudson's account.

Public appreciation of transparency was a necessary but insufficient condition for effective policy change, however. Schudson cites a review of the first decade of the Fair Packaging and Labeling Act that suggested persistent confusion among consumers about product packaging standards and requirements for the "open dating” of foods. Indeed, consumer-oriented reforms may score fewer points in the absence of a well-educated consumer base. 
Thus to say that we are still living in the "Sunshine Era"—-saturated with the culture of transparency and reforms aimed at promoting it-is not to admit that transparency is always an effective policy tool. Nor, as Schudson notes in his conclusion, is transparency universally accepted as a public good. Within minutes of the launch of the federal government's Physician Compare website in 2015, which enabled consumers to see doctors’ performance on routine screenings and preventive care for chronic conditions, the American Medical Association snapped back that the data would "lead consumers to draw faulty inferences about the quality of care that an individual physician or group provides” (Evans 2015). For the AMA, as for other professional groups, the opposite of transparency is not always secrecy; rather, it is the judgment of professionals, whose reputation is conditioned on social trust. Indeed, as Schudson acknowledges, the ideology of transparency continues to sit uneasily with professional beliefs about when and where the release of information is appropriate. Thus the social transformation documented in The Rise of the Right to Know is incomplete. Nevertheless, as the efforts of the Obama administration suggest, shifts in public culturehave made transparency a concept worthy of presidential energy.

\section{TURNING OUT THE LIGHTS}

If Schudson is right about the endurance of skepticism towards transparency, then studying the implementation of open-government policies is not enough. By focusing on "Sunshine Laws" themselves, we miss other trends in public policy that cut in the opposite direction, restricting and controlling the flow of information in a way that undermines the goals of "open government” and democratic deliberation. In Legislating in the Dark, James M. Curry shows 
how policymakers restrict access to information—rather than expand it—in order to shape public policy.

Just as transparency reformers seek to open up the policymaking process to new participants, Curry argues that party leaders in the House of Representatives have strong incentives to limit access to information about the content of legislation that might elicit controversy. Information about the content of bills under consideration is an especially valuable commodity in the House, where rank-and-file members have little time to become experts on most policy topics, and have little access to resources that allow them to analyze legislation on the agenda. Party leaders have become information "vendors," developing legislative summaries and talking points that "sell” features of the legislation that will be particularly appetizing to the rank-and-file.

Studying the process of information control is not easy. For obvious reasons, the decision to restrict information about legislation is itself a low-visibility affair. Tactics are developed behind closed doors and are rarely spoken about in public. As such, Curry’s empirical strategy relies on participant observation, based on the author's extended periods of time as a congressional staffer, as well as interviews with policy elites and quantitative analyses of major legislation introduced between 1999 and 2010. As a result of this shoe-leather political science, Curry is able to identify and analyze fresh empirical patterns—-well known to actors "on the ground” in Congress, but absent from scholarly debates. In Chapter 3, Curry shows how party leaders collect information about members’ policy preferences and use this information to structure how they frame legislation. With this information, members develop memoranda and legislative summaries that “package” their priority legislation. For example, in descriptive memos supporting legislation that would ensure a negative assessment of ethanol by the 
Environmental Protection Agency, Republican leaders framed the bill to members as noncontroversial legislation, designed to ensure that the agency did due scientific diligence before approving the use of ethanol.

Armed with a nuanced qualitative understanding of leadership-driven information control, Curry systematically examines 518 important bills for evidence of these tactics. In 29.5 percent of these cases, parties used a "restricted layover" tactic, in which the full text of legislation is made available to members for 24 hours or less before a floor vote. For 19.5 percent of the bills in Curry's data set, party leaders used the tactic of "self-execution," in which the House Rules Committee alters the contents of legislation through a procedural vote before a bill is considered on the floor. Finally, in 12.7 percent of the bills, party leaders significantly increased the complexity of legislation—often through creating massive omnibus bills or stuffing legislation with technical jargon. Party leaders use all of these tactics with greater frequency on legislation they consider a high priority, especially when organized interests and multiple congressional committees are attentive to a bill.

How does the restriction of information shape public policy? It empowers partisan elites. When party leaders "turn out the lights," Curry shows that roll call votes divide more sharply along party lines. By restricting information, party leaders limit the ability of rank-and-file members to analyze the content of legislation and assess its proximity to their own preferences. These tactics thus result in more responsible parties, yet they also limit input from rank and file members—and potentially constituents—on the content of legislation. Whatever normative conclusions one might draw from Legislating in the Dark, this book powerfully shows how information shapes the substance of public policy and the quality of democratic representation in the United States. 


\section{PUBLIC KNOWLEDGE AS PUBLIC POLICY?}

Transparency advocates often assume that better access to information empowers government watchdogs, voters, and consumers to shape public policy. This view is premised on a belief in unorganized individuals' ability to process or aggregate information, or in government's willingness and capacity to translate information in ways that can be easily acted upon. For those who hold this belief, the books discussed here suggest a wide array of options to improve the "effectiveness" of transparency tools—-from ensuring that officials charged with oversight have appropriate incentives and applying appropriate punishments for violating disclosure laws to designing transparency programs with a better sensitivity to how information will be used.

Yet these books also give us reason to doubt that transparency is the wide, well-paved, and toll-free road out of contemporary policy dilemmas that its most vociferous advocates claim. As transparency has risen to prominence as a policy instrument, a series of new political disputes emerged over what information may be public, in what form, to whom, and at whose discretion.

These disputes carry three important lessons. First, the implementation of open government depends on legislative and bureaucratic infrastructures that were not built with transparency in mind. Those affected by the reforms also tend to find clever workarounds. To address these governance gaps, we need to better understand how government organizations enact new material practices of transparency, and why these practices sometimes fail to take hold (Worthy 2015). Second, transparency measures appear to require healthy public appetites for information, despite persistent voter and consumer myopia. As such, we need to know more about how publics become more effectively enrolled in the implementation of open government. Finally, and perhaps most importantly, given the limits of transparency as a policy instrument, we need to think more carefully about the political conditions of its use-especially as an 
alternative to formal regulatory or economic incentives. Under what conditions, and with what coalitions, is transparency more than a cosmetic "show of doing something”? And when can policymakers enhance the effectiveness of disclosure by hitching it to other policy tools? With answers to questions like these, we stand a better chance of getting transparency politics right.

\section{REFERENCES}

Evans, Melanie. 2015. “CMS Posts New Quality Data for Individual Doctors over AMA Protests,” Modern Healthcare, December 10, 2015, available: http://www.modernhealthcare.com/article/20151210/NEWS/151219991

Gitelman, Lisa, ed. 2013. "Raw Data” is an Oxymoron. Cambridge, MA: The MIT Press. Hudak, John and Grace Wallack. 2015. Sometimes cutting budgets raise deficits: The curious case of inspectors' general return on investment. Center for Effective Public Management. Washington, DC: Brookings Institution.

Lee, Kenneth, Kreshnik Hoti, Jeffrey D. Hughes, and Lynne M. Emmerton. 2014. "Interventions to Assist Health Consumers to Find Reliable Online Health Information: A Comprehensive Review.” PLoS One 9(4): e94186.

Obama, Barack. 2009. Memorandum on Transparency and Open Government. Accessed December 12, 2015. Available: https://www.whitehouse.gov/the_press_office/TransparencyandOpenGovernment.

---. 2013. Executive Order-- Making Open and Machine-Readable the New Default for Government Information. Accessed December 12, 2015. Available: https://www.whitehouse.gov/the-press-office/2013/05/09/executive-order-making-openand-machine-readable-new-default-government-

Open Government Partnership. 2013. Second Open Government National Action Plan for the United States of America. December 5. Accessed December 12, 2015. Available: https://www.whitehouse.gov/sites/default/files/docs/us_national_action_plan_6p.pdf

Rourke, Francis E. 1961. Secrecy and Publicity: Dilemmas of Democracy. Baltimore, MD: Johns Hopkins Press.

Shils, Edward. 1956. The Torment of Secrecy. New York: Free Press.

Turner, Cory. 2015. "President Obama's New 'College Scorecard' Is A Torrent Of Data.” National Public Radio, September 12. Accessed December 12, 2015. Available: http://www.npr.org/sections/ed/2015/09/12/439742485/president-obamas-new-collegescorecard-is-a-torrent-of-data

Worthy, Ben. 2015. The Impact of Open Data in the UK: Complex, Unpredictable, and Political, Public Administration, 93(3), pp. 788-805. 